\title{
Incidental Detection of Persistent Left Superior Vena Cava during Transvenous Pacing
}

${ }^{1}$ S Subash, ${ }^{2}$ Divya Gopal, ${ }^{3}$ Ashwini Thimmarayappa

\begin{abstract}
Patients with persistent left superior vena cava (PLSVC) are usually asymptomatic, but due to its anatomical defects, difficulties in establishing central venous access, pacemaker implantation and cardiothoracic surgery are common. We report a case of 65 years old patient who presented with complete heart block in cardiac critical care and, after emergency transvenous pacing, the chest X-ray showed unusual course of the transvenous pacing lead, which on further transthoracic echocardiographic (TTE) evaluation demonstrated dilated coronary sinus with PLSVC.
\end{abstract}

Keywords: Dilated coronary sinus, Persistent left superior vena cava, Transvenous pacing.

How to cite this article: Subash S, Gopal D, Thimmarayappa A. Incidental Detection of Persistent Left Superior Vena Cava during Transvenous Pacing. J Perioper Echocardiogr 2015; 3(2):52-54

\section{Source of support: Nil \\ Conflict of interest: None}

\section{INTRODUCTION}

Persistent left superior vena cava (PLSVC) can be incidentally detected during transvenous pacemaker implantation in cardiac intensive care. ${ }^{1}$ Persistent left superior vena cava can give a false perception of central venous catheter placement in mediastinum, pericardium, left internal mammary vein, subclavian or carotid artery. Anesthesiologists may come across such rare cases in cardiac intensive care and we hereby discuss the importance of transthoracic echocardiographic (TTE) in cardiac critical care.

\section{CASE REPORT}

A 65 years old male patient with acute inferior wall myocardial infarction and right-sided hemiparesis supported

\footnotetext{
${ }^{1}$ Resident, ${ }^{2}$ Assistant Professor, ${ }^{3}$ Associate Professor

${ }^{1-3}$ Department of Cardiac Anesthesia, Sri Jayadeva Institute of Cardiovascular Sciences and Research, Bengaluru Karnataka, India

Corresponding Author: S Subash, Resident, Department of Cardiac Anesthesia, Sri Jayadeva Institute of Cardiovascular Sciences and Research, Bengaluru, Karnataka, India, Phone: 9945037670, e-mail: sssubash@yahoo.com
}

with mechanical ventilation was referred to our institute for further management. Patient's heart rate was 40/min, blood pressure: $90 / 60 \mathrm{~mm} \mathrm{Hg}$ and pulse oximetry saturation: $\left(\mathrm{SpO}_{2}\right) 100 \%$. His electrocardiogram (ECG) showed bradycardia with complete heart block. The reversible causes of bradycardia, such as hypoxia, acidosis, electrolyte imbalances and history of intake of long-term medications were ruled out. The patient was paced through right internal jugular vein (RIJV) using a semirigid transvenous pacing lead of size 6 FR. The pacing spikes were seen when the pacing lead had passed a distance of approximately $27 \mathrm{~cm}$ from skin. The pacing was also confirmed by the palpation of radial pulse. Effective pacing was accomplished with output of $2.0 \mathrm{~mA}$, sensitivity of $3.0 \mathrm{mV}$ and heart rate of $80 / \mathrm{min}$. Patient's hemodynamics were stable with a blood pressure of $100 / 62 \mathrm{~mm} \mathrm{Hg}$, central venous pressure of $4 \mathrm{~mm} \mathrm{Hg}$, set heart rate of 80 beats $/ \mathrm{min}$ and $\mathrm{SpO}_{2}$ of $98 \%$ with $0.6 \mathrm{FiO}_{2}$ on synchronized mode of mechanical ventilation. The check X-ray of chest showed right-sided pneumothorax along with unusual course of the transvenous pacing lead (Fig. 1). An intercostal drainage tube was inserted for pneumothorax. The abnormal course of pacing lead on X-ray led to the suspicion of its improper placement. So, it was decided to pace through femoral vein along with removal of RIJV catheter under fluoroscopic guidance. However, TTE demonstrated the presence of the pacing lead in the right ventricle (RV) which had passed through dilated coronary sinus and right atrium (RA) (Fig. 2, Video 1) without any evidence of pericardial collection. Agitated saline test done through the peripheral cannula on left arm demonstrated early opacification of dilated coronary sinus followed by RA and RV which confirmed the presence of PLSVC (Fig. 3, Video 2). Hence, the patient was not shifted to catheterization laboratory for any interventions.

\section{DISCUSSION}

Persistent left superior vena cava, first described by Edwards and DuShane, is an uncommon anatomical variant present in 0.3 to $0.5 \%$ of general population and, when associated with other congenital anomalies, the incidence is $10 \%{ }^{2}$ Persistent left superior vena cava can be associated with cardiac anomalies like atrial septal defect, bicuspid aortic valve, coarctation of aorta, coronary sinus 


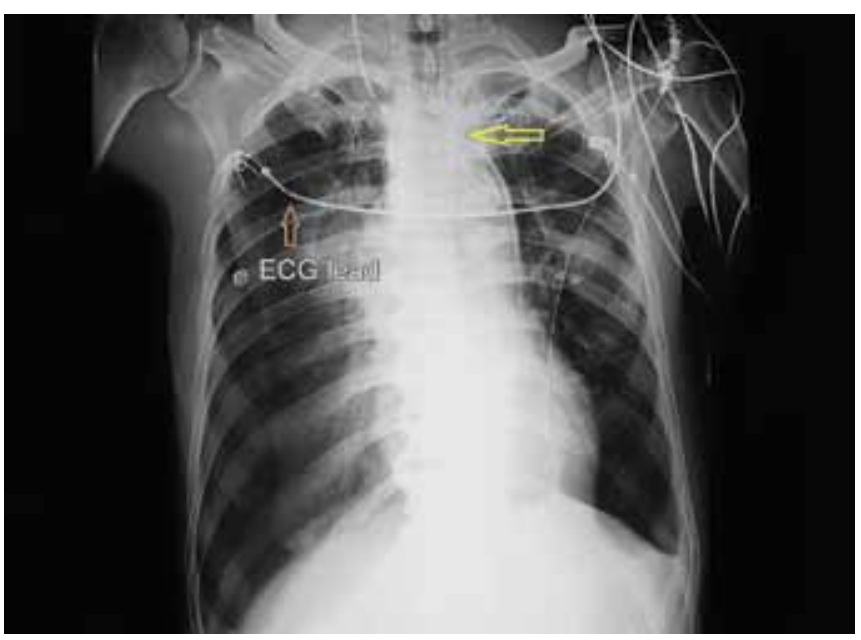

Fig. 1: Chest X-ray showing abnormal left paramediastinal course of pacing wire (yellow arrow) and right-sided pneumothorax

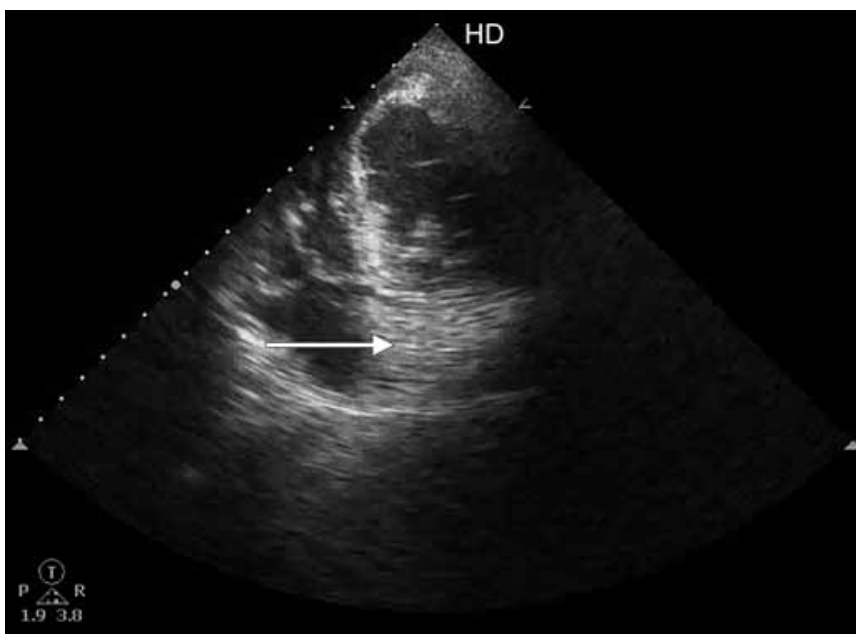

Fig. 3: Apical four-chamber view with posterior tilt of probe, arrow showing early opacification of dilated coronary sinus following bubble contrast injection through left-sided intravenous cannula

ostial atresia and cor triatriatum, in $40 \%$ of patients. ${ }^{3}$ Embryologically, PLSVC is due to the persistence of patent left anterior cardinal vein. ${ }^{4}$

Persistent left superior vena cava is associated with absent innominate vein in $65 \%$ of cases. It drains into RA via coronary sinus in 80 to $90 \%$ of individuals without any hemodynamic consequences. ${ }^{5}$

However, in our case, the unusual course of the pacing lead on chest X-ray was because of the presence of innominate vein probably connecting IJV or right SVC and PLSVC. Hence, the pacing lead had travelled through IJV, SVC, innominate vein, PLSVC, coronary sinus, RA to reach RV (Fig. 4). The presence of a persistent LSVC does not prevent successful placement of a pacemaker. ${ }^{6}$

Other possible causes where a dilated coronary sinus can be seen are elevated right atrial pressure, ${ }^{7}$ coronary arteriovenous fistula, ${ }^{8}$ partial anomalous pulmonary venous return ${ }^{9}$ and unroofed coronary sinus with left to right shunt. ${ }^{10}$ Presence of dilated coronary sinus in

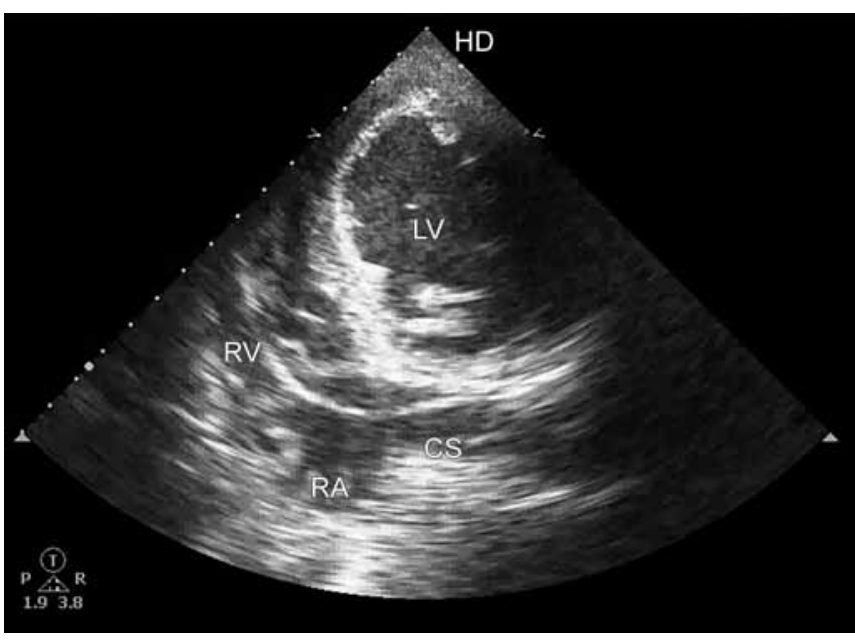

Fig. 2: Transthoracic apical view showing the course of the pacing lead into right ventricle via dilated coronary sinus and right atrium

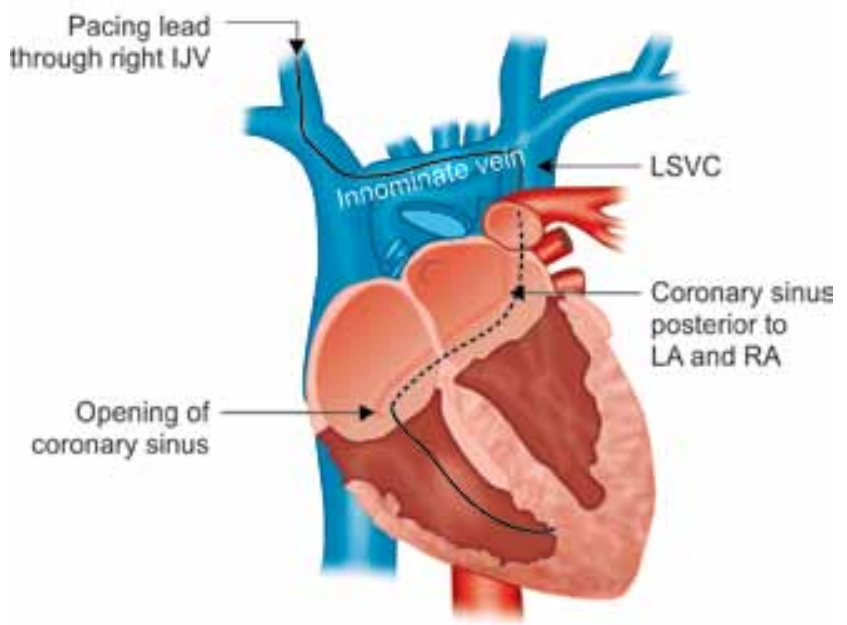

Fig. 4: Pictorial representation of the course of pacemaker lead

the absence of elevated right atrial pressure, bubble contrast study through left arm vein which demonstrates enhancement of dilated coronary sinus before RA, favors the presence of PLSVC by TTE. Other modalities to diagnose PLSVC are multiplane transesophageal echocardiography with contrast radionuclide angiocardiography, multislice spiral computed tomography and magnetic resonance venography. ${ }^{11}$

\section{CONCLUSION}

Catheter placement, when done without ultrasound guidance, is a blind procedure, and migration of guidewire remains a known complication. The guidewire could migrate cranially, toward ipsilateral arm or can take an abnormal left paramediastinal intrathoracic course, as in our case report. The possibility of PLSVC could be considered whenever such abnormal course of guidewire on CXR is seen. Knowledge of transthoracic echocardiography is essential for cardiac anesthesiologists in the critical care setup. 


\section{REFERENCES}

1. Heather LR, Mohammed Y, Wesley RL, Brent EW. Persistent left superior vena cava: Case reports and clinical implications. Int J Cardiol 2006 Nov;113(2):242-246.

2. Biffi M, Bertini M, Ziacchi. Clinical implications of left superior vena cava persistance in candidates for pacemaker or cardioverter - defibrillator implantation. Heart Vessels 2009 Mar;24(2):142-146.

3. Sarodia B, Stoller J. Persistent left superior vena cava: case report and literature review. Respir Care 2000 Apr;45(4): 411-416.

4. Meijer SBM, Mac Gillavry MR, Tan HL. Left superior vena cava, a remnant of embryological development. Neth Heart J 2008 May;16(5):173-174.

5. Webb W, Gamsu G, Speckman J, Kaiser J, Federle M, Lipton M. Computed tomographic demonstration of mediastinal venous anomalies. Am J Roentgenol 1982 Jul;139(1):157-161.

6. Fraser R, Dovrkin J, Rosall R. Left superior vena cava. Am J Med 1961 Nov;31(5):711-716.
7. Brian CK, Bahram K, Mirielle A, Lori BD, Anthony ND, Daniel GB. The dilated coronary sinus: utility of coronary sinus cross-sectional area and eccentricity index in differentiating right atrial pressure overload from persistent left superior vena cava. Echocardiography 2011 Sep;28(8):829-832.

8. Sung HJ, Won CC, Suk JC, Hyun S, Cheol HC. Multiple coronary arteriovenous fistulas to the coronary sinus with an unruptured coronary sinus aneurysm and restrictive coronary sinus opening to the right atrium. Circulation 2009 Sep;120(12):1138-1140.

9. Ammash NM, Seward JB, Wavnes CA, Connolly HM, O'Leary PW, Danielson GK. Partial anomalous pulmonary venous connection: diagnosis by transesophageal echocardiography. J Am Coll Cardiol 1997 May;29(6):1351-1358.

10. Huang XS. Partially unroofed coronary sinus. Circulation 2007 Oct 9;116(15):e373.

11. Podolsky L, Jacobs L, Schwartz M, Kotler M, Ioli A. Transesophageal echocardiography in the diagnosis of the persistent left superior vena cava. J Am Soc Echocardiogr 1992 Mar-Apr;5(2):159-162. 